\begin{tabular}{|c|c|c|}
\hline 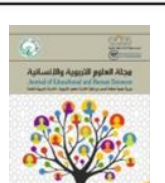 & $\begin{array}{r}\text { وية والإنسانية } \\
\text { Journal of Education } \\
\text { www.je }\end{array}$ & $\begin{array}{l}\text { مجلة العلور Human Sciences } \\
\text { I com }\end{array}$ \\
\hline & Volume (7) September 2021 & العدد (7) سبتمبر 2021 \\
\hline
\end{tabular}

\title{
حملة الاناضول الأولى والثانية (1389-1391)
}

\author{
م. فاطمة عبدالجليل ياسر

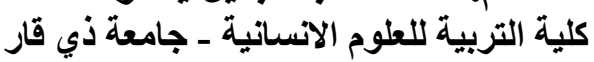 \\ m.fatma.a@utq.edu.iq
}

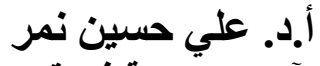

كلية الآداب - جامعة ذي قين قار

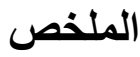

انتهجت الدولة العثمانية اساليب مختلفة في تعاملها مع الامارات التركمانية في الاناضول خلال القرن الرابع عشر الميلادي تبعا للظروف السياسية آنذاك و التي تمثلت بالمصاهرة السياسية او الحرب او شر اء الاراضي ذات مواقع هامة من بعض الامارات التركمانية، الا ان في عهد السلطان بايزيد الاول اعتمد سياسة مغايرة عن سابقين من السلاطين تجاه الامار ات التركمانية والتي تمثلت بالضم و الالحاق السريعة بالدولة العثمانية، ولعل السبب في ذلك يعود الى ان تللك الامارات كانت كثير ما تحدث اضطر ابات والفوضى في الاناضول والتي كانت مصدر قلق بلق للاولة العثمانية التي ادت الى ان تعيق تقدم وتوسع الدولة العثمانية في الروملي. لذا بادر السلطان بايزيد الاول الى فرض سيطرته على الامارات التركمانية في غرب الاناضول والتهي التي تمثلت

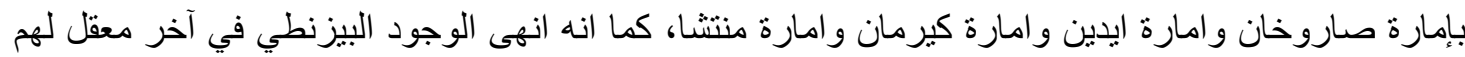
في الاناضول التي تمنلت بمدينة الاشهر، كما قاد في حملته الثانية ال قضاء على الامارات التركمانية في وسط وجنوب الاناضول وهي إمارة القرامان وامارة تكة وامارة حميد، وبهذا ان سياسة السلطان بايزيد الاول تجاه

الامار ات التركمانية كانت الهدف منها القضاء وبشكل نهائي على تلك الامار ات و الحقها بالدولة العثمانية.

الكلمات المفتاحية: السلطان بايزيد الاول، الدولة العثمانية، الامار ات التركمانية، الاناضول. 


\title{
First and Second Anatolian Campaign (1389-1391)
}

\author{
Prof. Dr. Ali Hussein Nimr
}

\author{
Lect. Fatimah AbdulJaleel Yassir \\ m.fatma.a@utq.edu.iq
}

\begin{abstract}
The Ottoman Empire adopted various methods in its dealings with the Turkmen emirates in Anatolia during the fourteenth century $\mathrm{AD}$, depending on the political circumstances at the time, which were political intermarriage, war, or the purchase of lands with important sites from some Turkmen emirates, but during the reign of Sultan Bayezid I, he adopted a different policy than the previous ones. From the sultans towards the Turkmen emirates, which was represented by the rapid annexation and annexation of the Ottoman state, and perhaps the reason for this is due to the fact that those emirates often caused unrest and chaos in Anatolia, which was a source of concern for the Ottoman state, which led to impeding the progress and expansion of the Ottoman state in Rumli.

Therefore, Sultan Bayezid I took the initiative to impose his control over the Turkmen emirates in western Anatolia, which were represented by the Emirate of Sorokhan, the Emirate of Aydin, the Emirate of Kerman and the Emirate of Mancha. The Turkmen in central and southern Anatolia, which is the Emirate of Al-Qaraman, the Emirate of Tikka and the Emirate of Hamid, and thus the policy of Sultan Bayezid I towards the Turkmen emirates was aimed at eliminating and definitively those emirates and their right to the Ottoman Empire.
\end{abstract}

Keywords: Sultan Bayezid I, the Ottoman Empire, the Turkmen Emirates, Anatolia. 


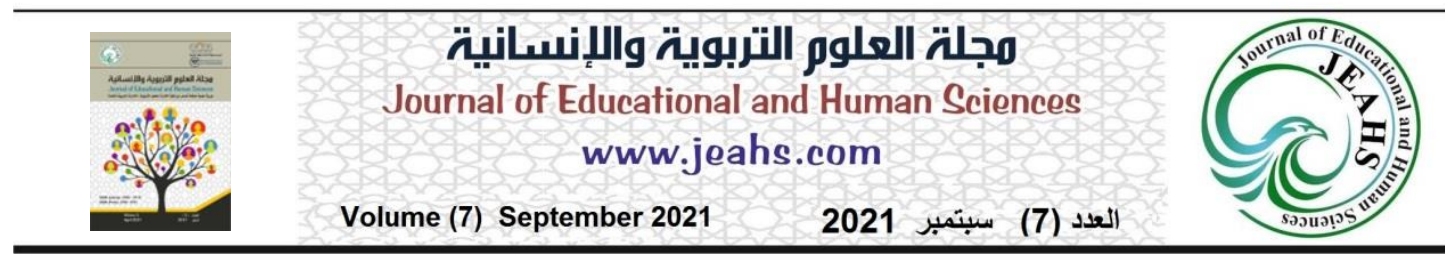

المقدمة

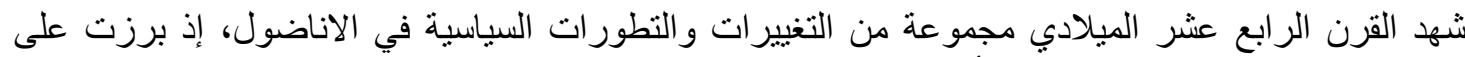

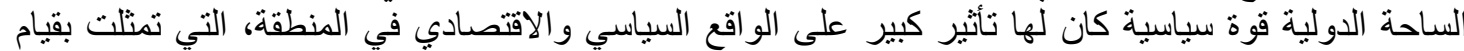

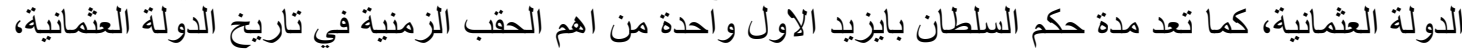

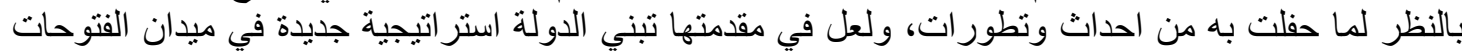

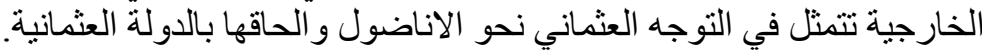

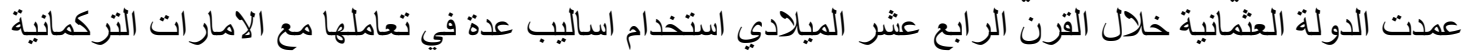

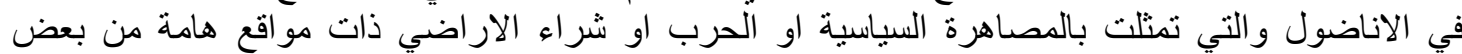

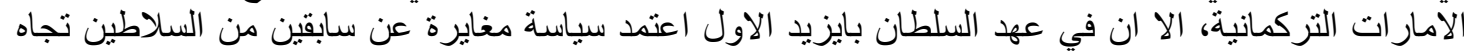

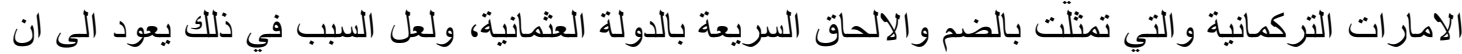

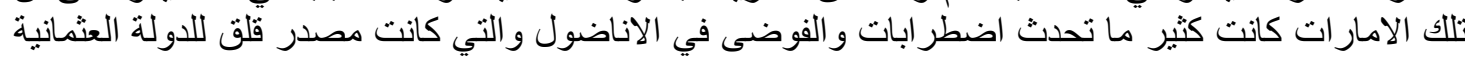

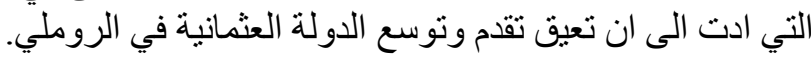

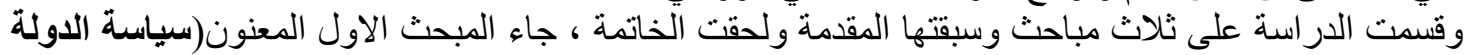

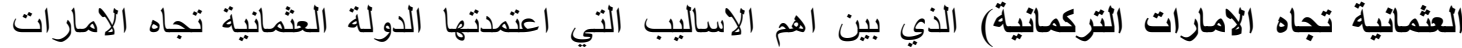

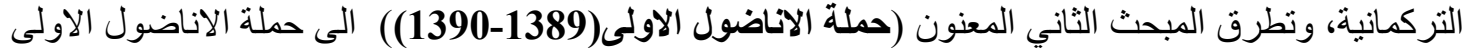

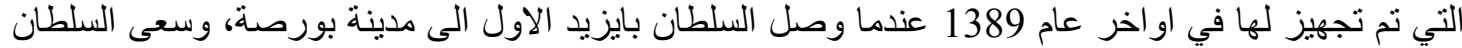

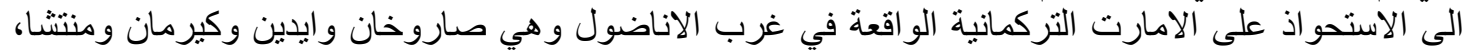

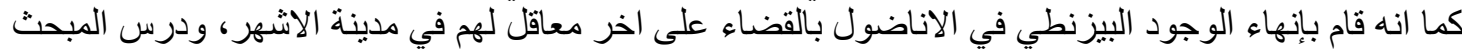

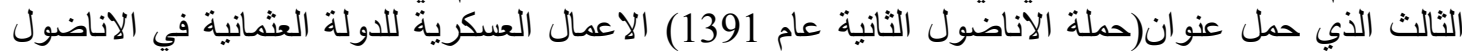

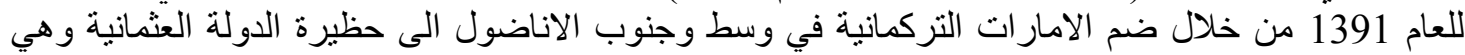

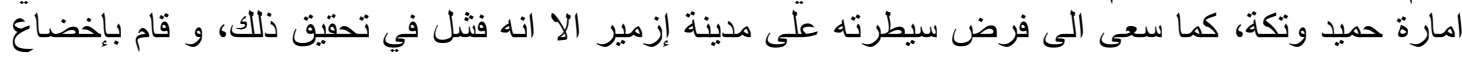

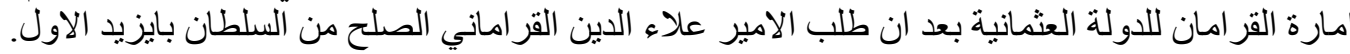

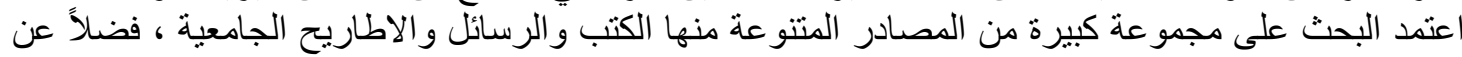

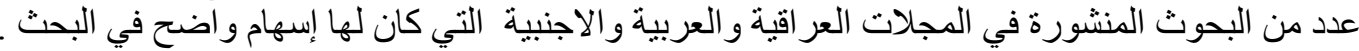

\section{المبحث الاول \\ سياسة الدولة العثمانية تجاه الامار الاول التركمانية}

سار السلطان بايزيد الاول على نهج اسلافه في الغزو و الفتح وتوسيع رقعة الدولة العثمانية، إذ استخل النصر

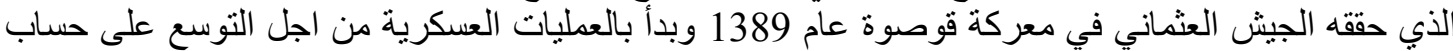

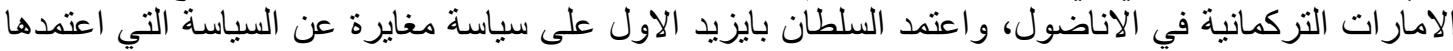

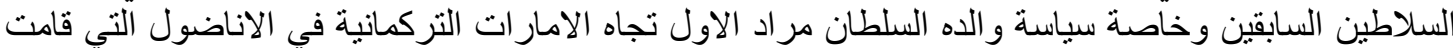

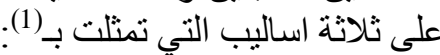

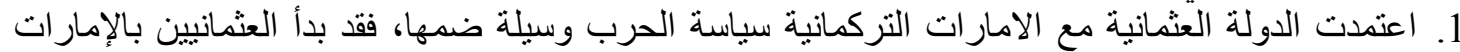

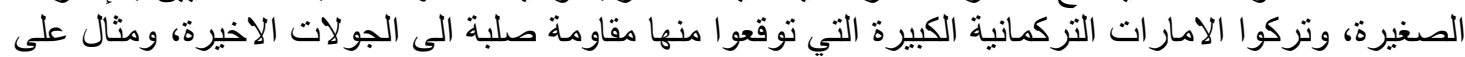

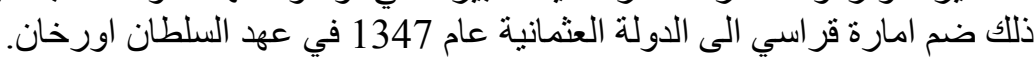

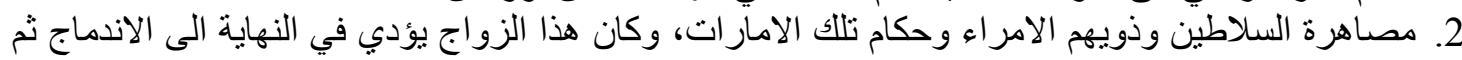

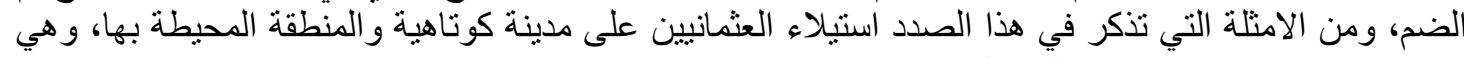

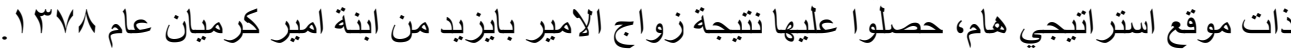

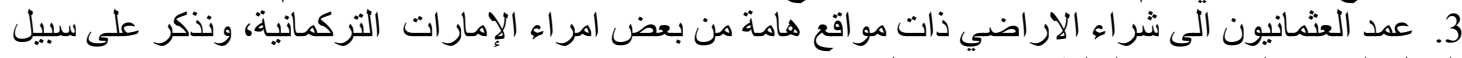

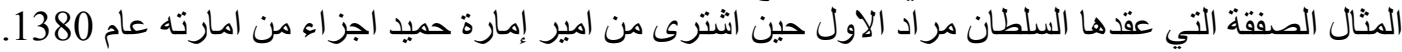

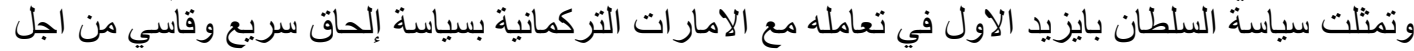




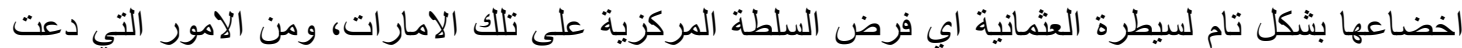

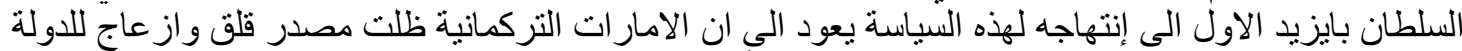

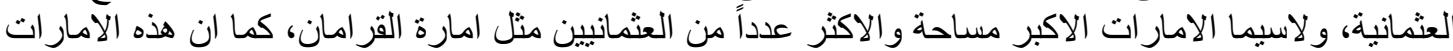

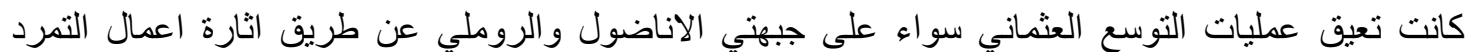
و القلاقل بين مدة و اخرى عيق (2).

\section{المبحث الثاني \\ حملة الاناضول الاولى(1389-1390)}

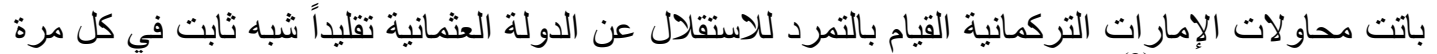

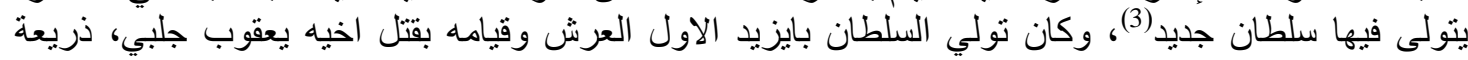

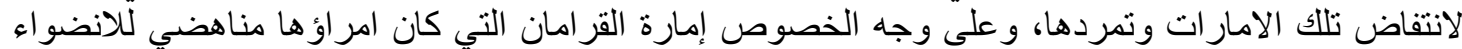

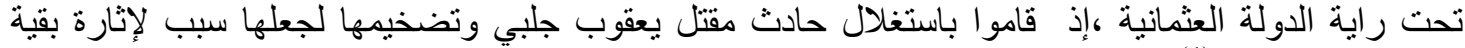

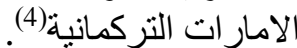
وحقيقة الامر، ان امر اء إمارة القرامان لم يكونوا يرغبون الأبون ان تمتد سيطرة ونفوذ الدولة العثمانية في الاناضول

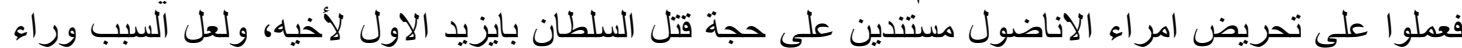

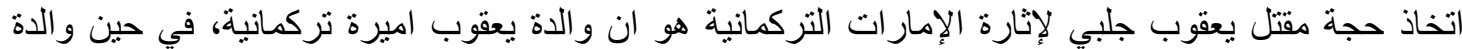

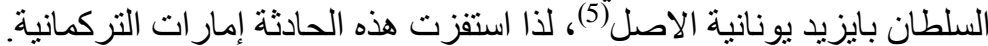

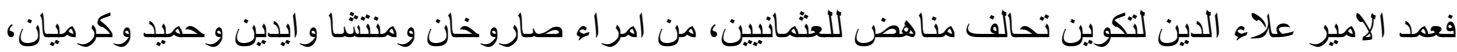

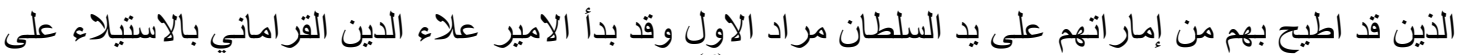

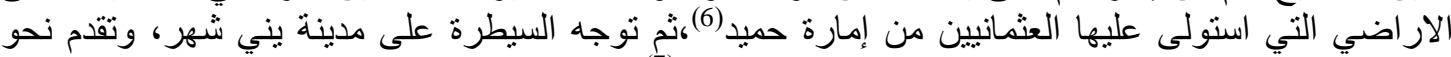

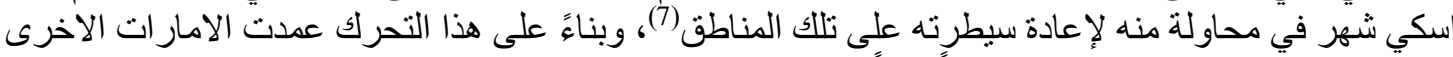

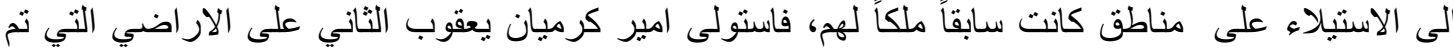

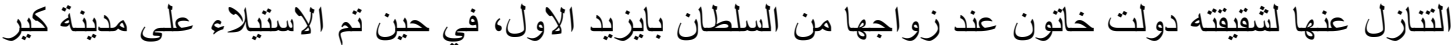

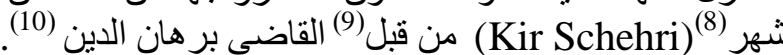

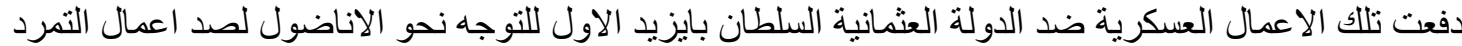

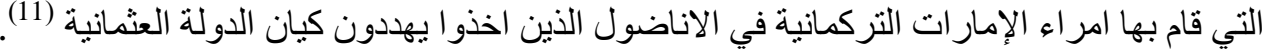

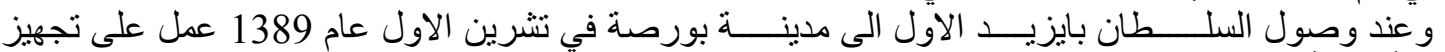

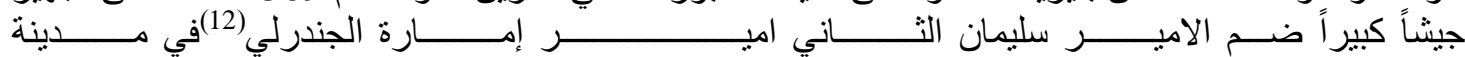

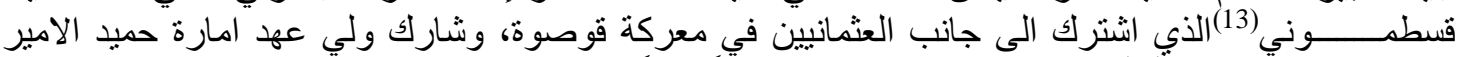

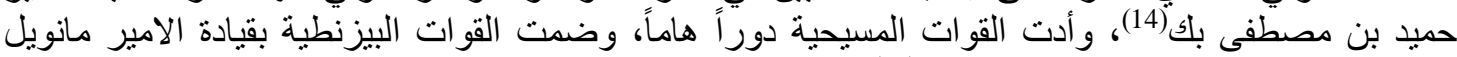

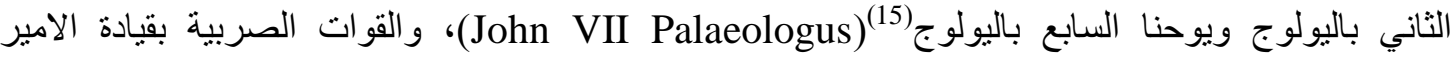

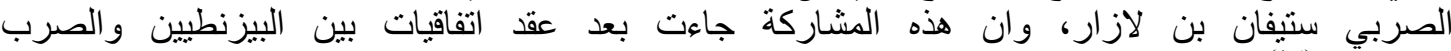

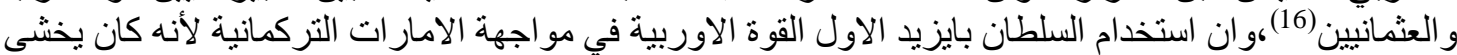

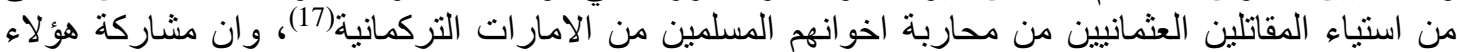

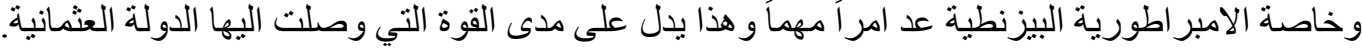

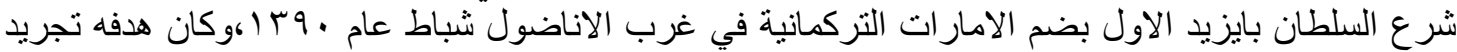

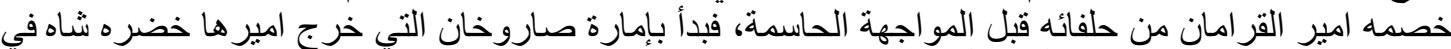

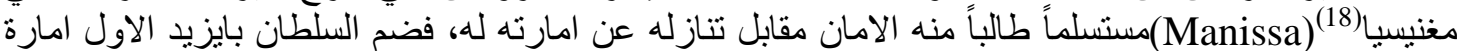

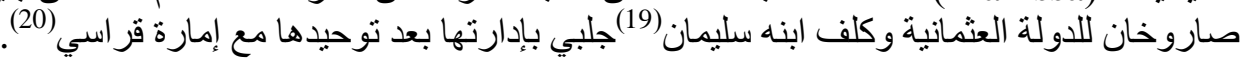

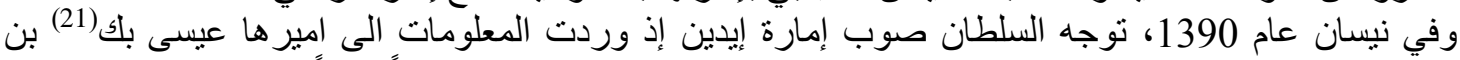

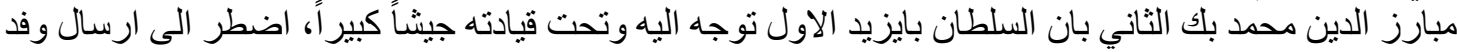

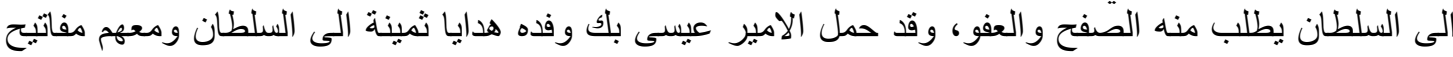




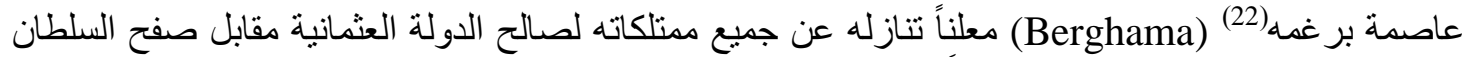

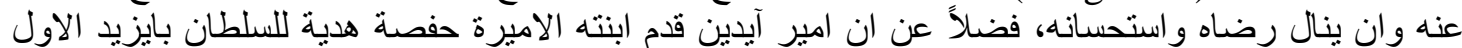

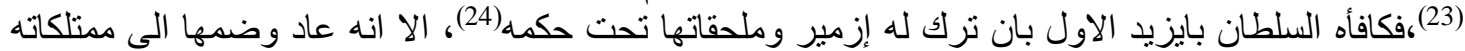

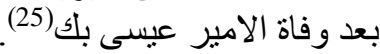

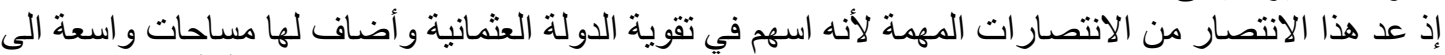

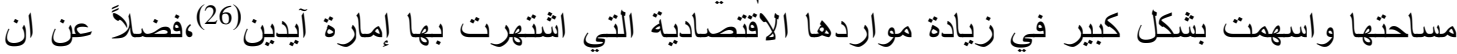

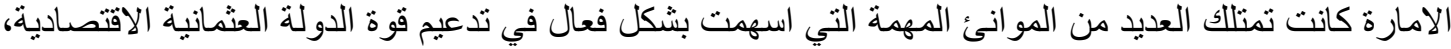

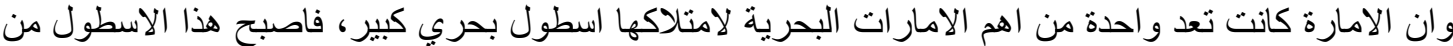

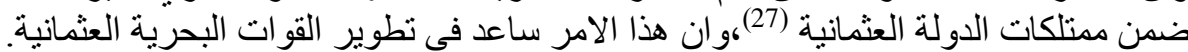

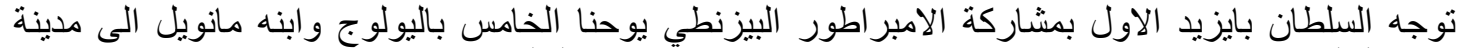

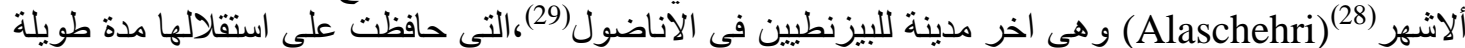

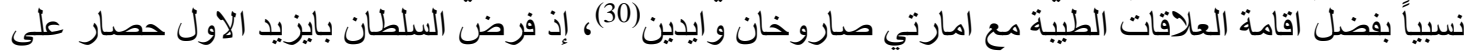

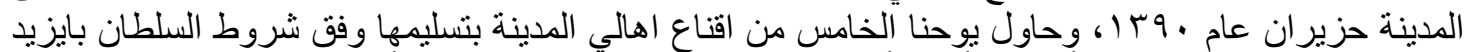

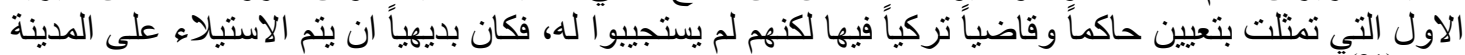

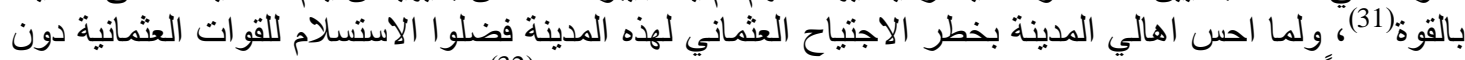

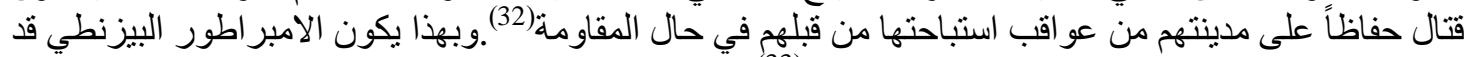

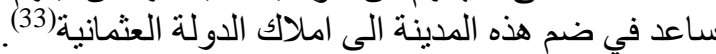

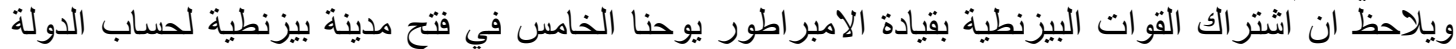
العثمانية، وهذا الامر في غاية الأهمية و الغر ابة الا انه يدل على مدى ضلى ضعف الأمبر اطورية البيزنطية يقابله قوة

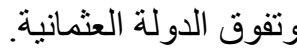

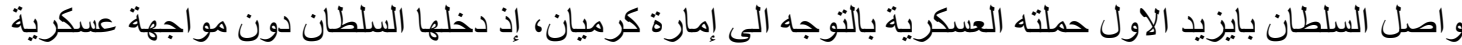

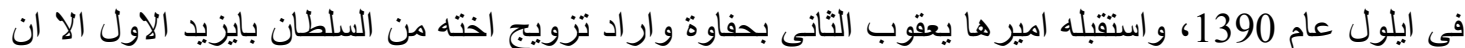

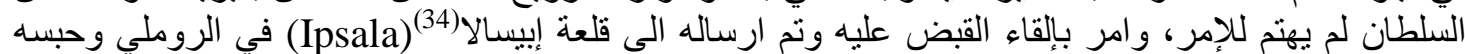

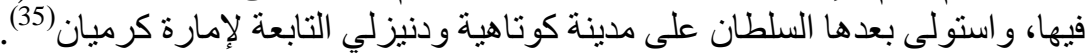

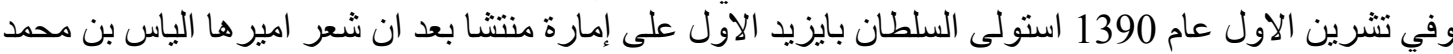

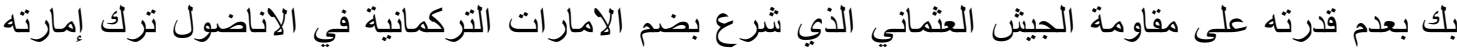

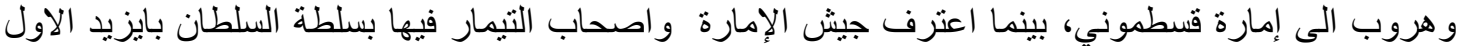

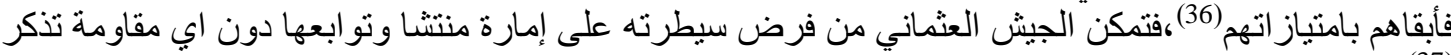

وامر السلطان بايزيد الاول بتعيين فيروز بك حاكماً على إمارة منتشا الذي عهد بالعمل على تنظيم شؤونها

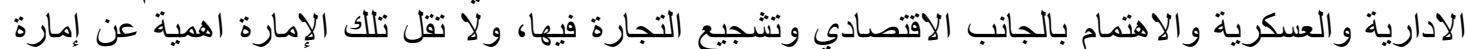

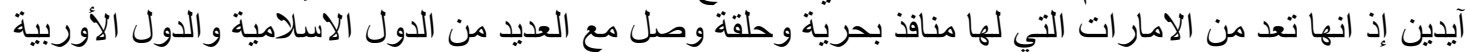

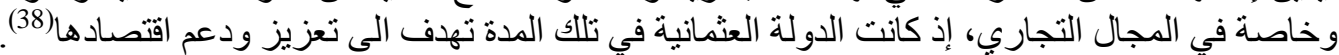

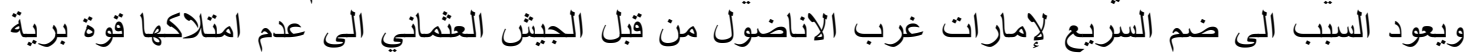

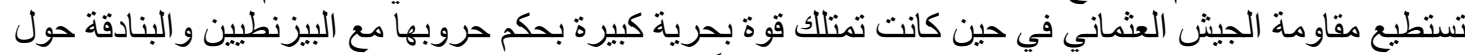

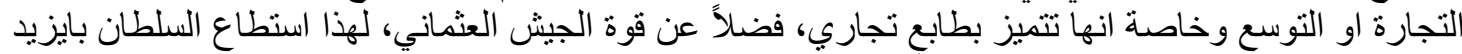

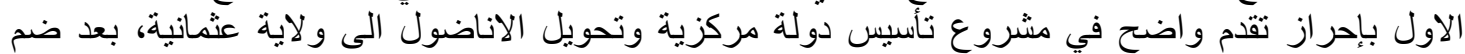

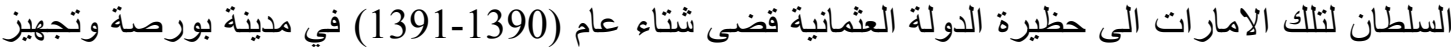
للحملة الاناضول الثانية ضد الامار ات التركمانية في وسطو وجنوب الانية الاناضول. 


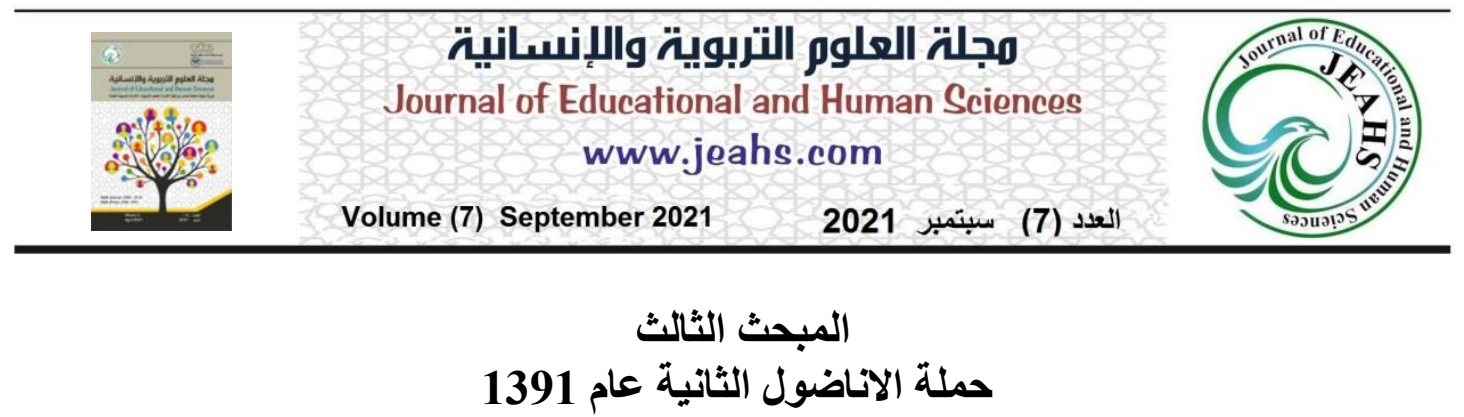

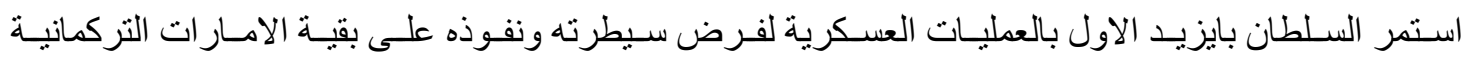

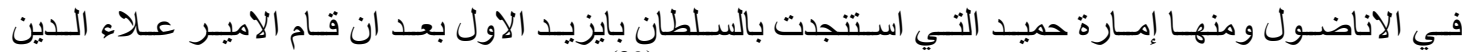

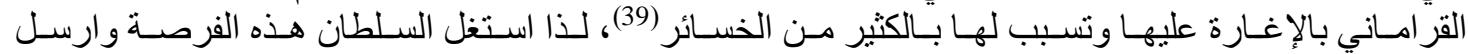

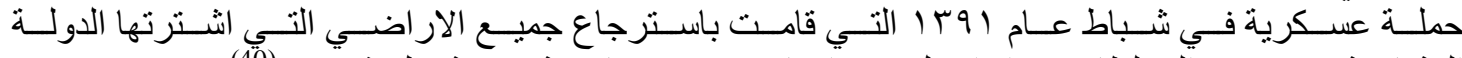

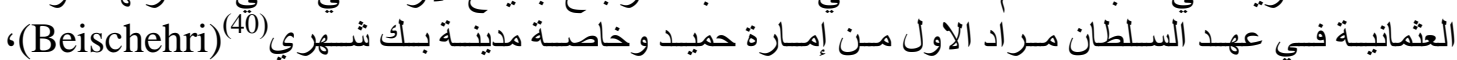

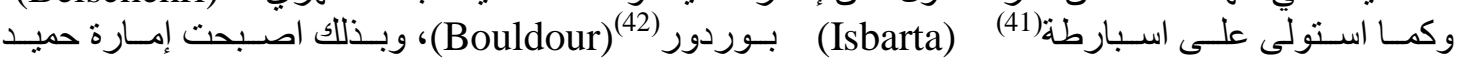

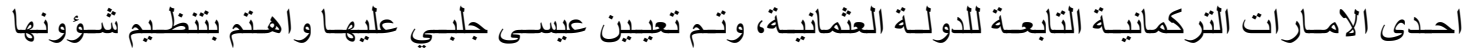

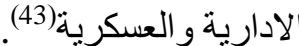
كما ارسل السلطان بايزيد الاول حملة عسكرية الى إمارة تكة تكونت من عشرين الف مقاتل بقيادة تيمور طاش عاش

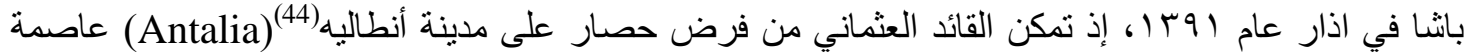

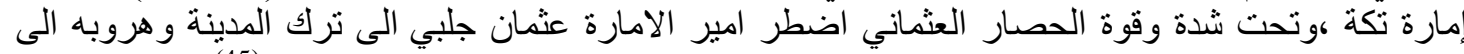

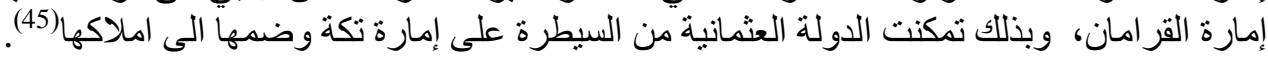

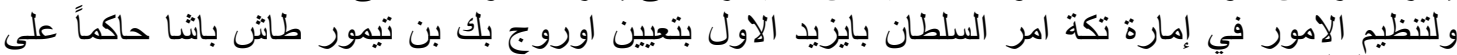

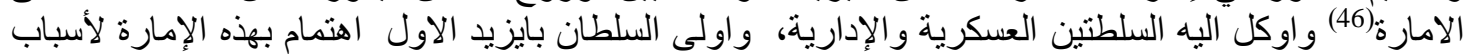

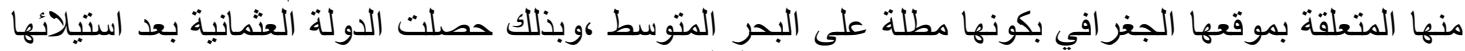

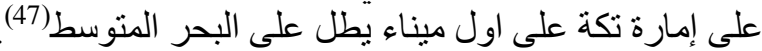

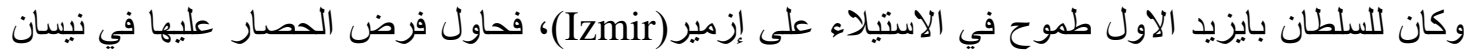

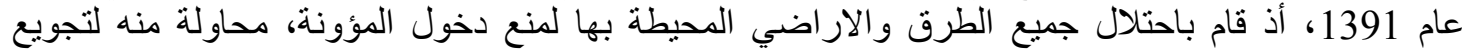

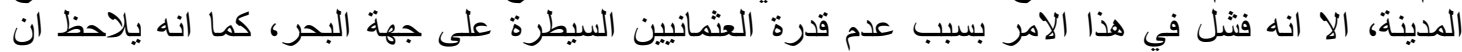

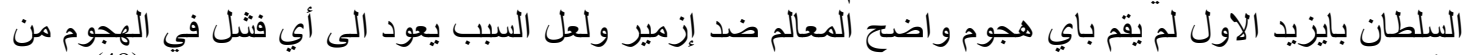

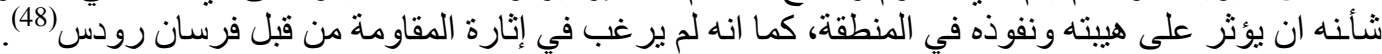

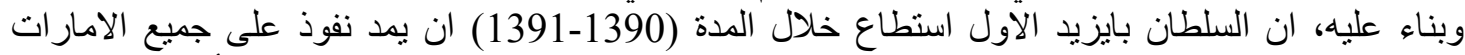

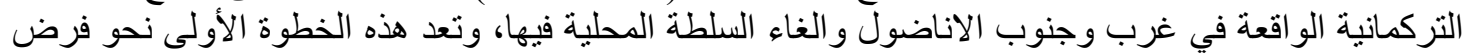
السلطة المركزية بجعل الاناضول التور احدى الايالات العثمانية.

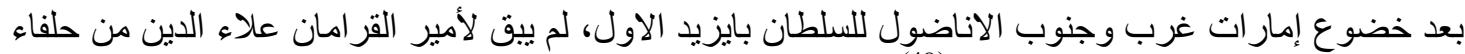

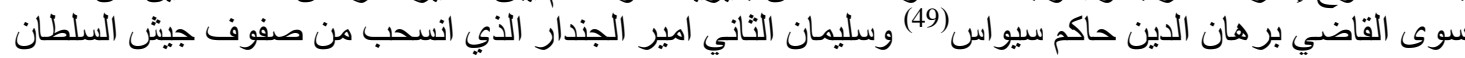

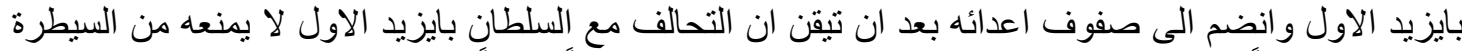

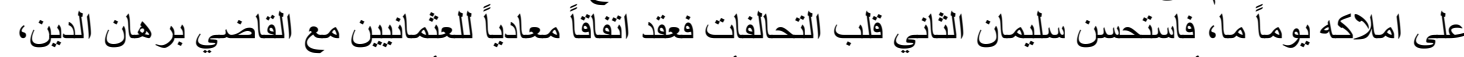

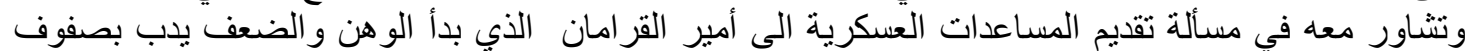
قو اته (50) توجه السلطان بايزيد الاول باتجاه حدود إمارة القرامان في ايار عام 1391، ولما علم الأمير علاء الدين بهذا

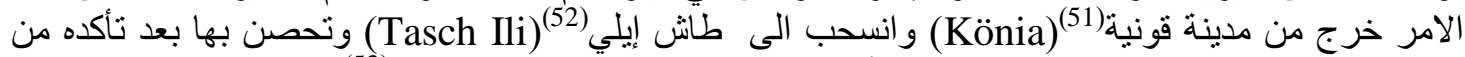

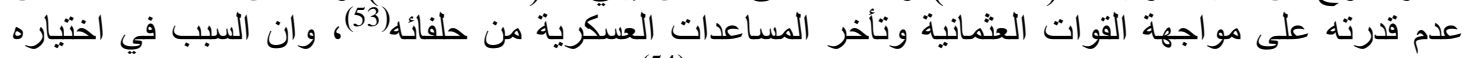

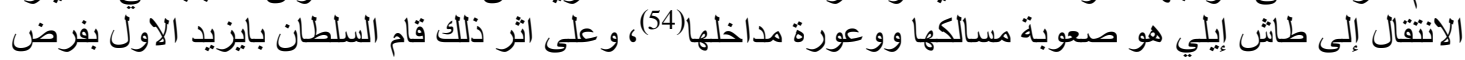

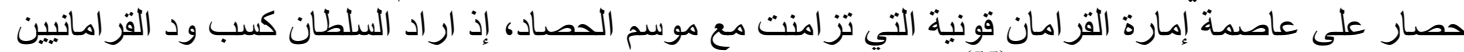

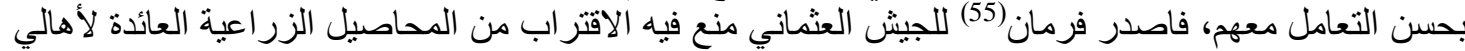

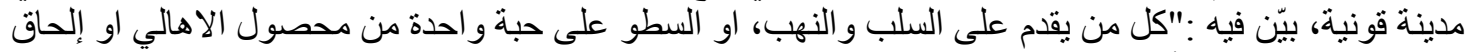

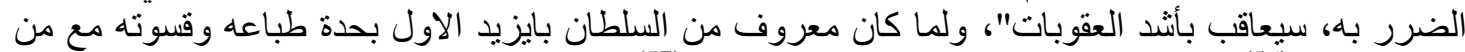

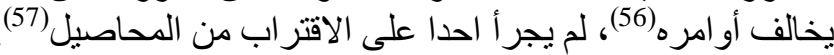

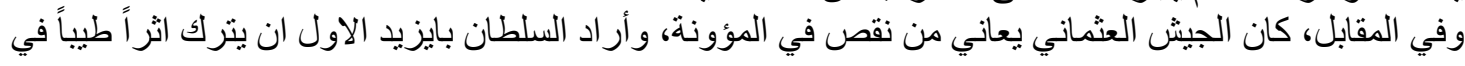




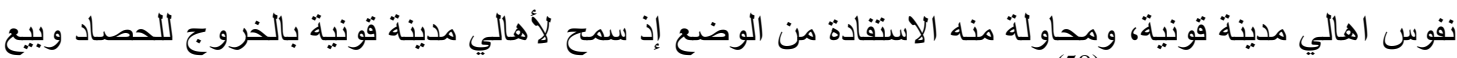

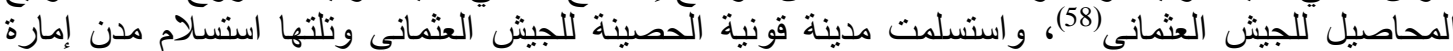

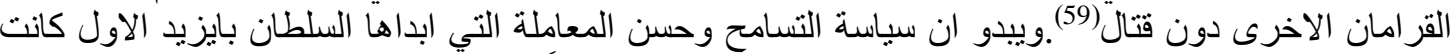

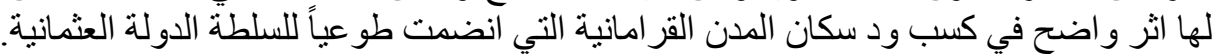
ونتج عن ذللك، اضطر ار الامبر علاء الدين الى طلب الصلح من السلطان بايزيد الاول الذي ولئي وافق عليه، وقد

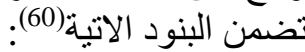
1. 1 يتعهد امير القرامان ان يكون مخلصاً وتابعاً للسلطان العثماني.

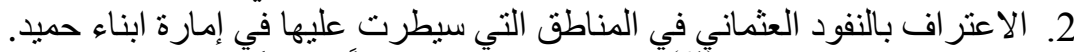

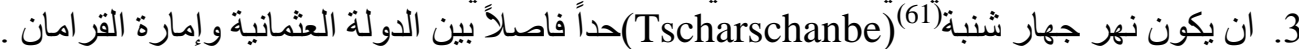

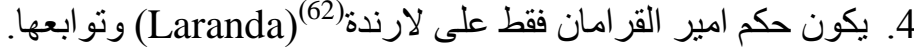

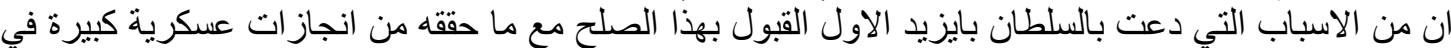

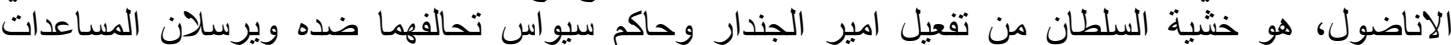

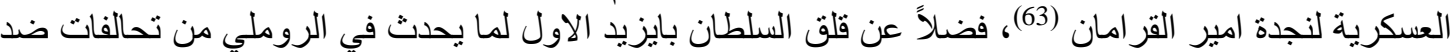

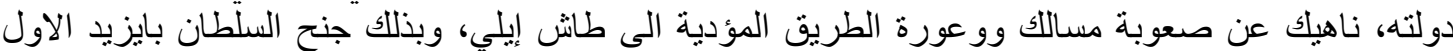

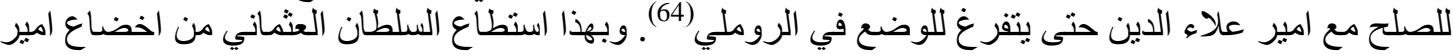

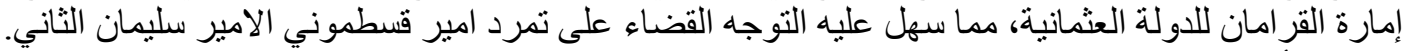

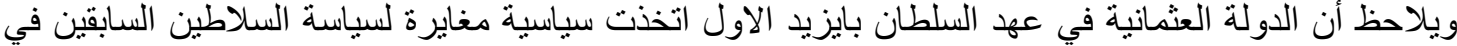

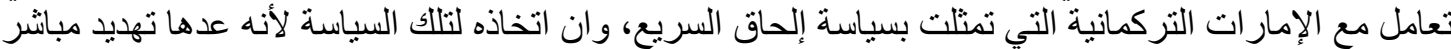

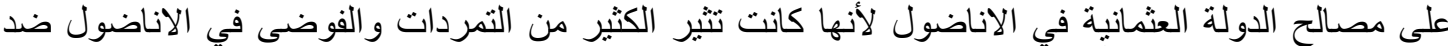

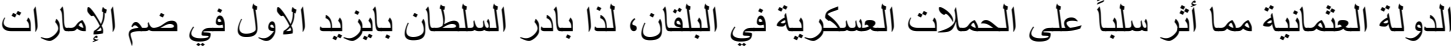

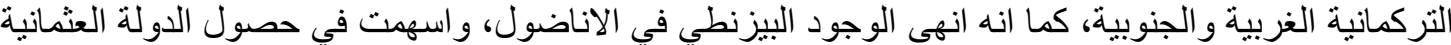

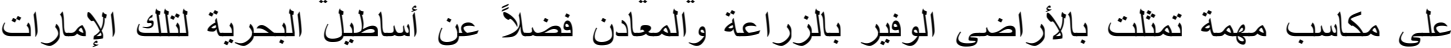

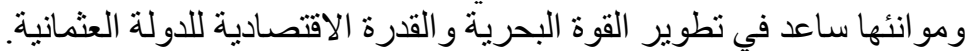

الخاتمة: بعد دراسة موضوع حملة الاناضول الاولى والثانية (1389-1391)، تم التوصل إلى جملة من الاستنتاجات

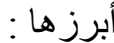
1. نالت الأناضول اهتماماً كبيراً من قبل السلطان بايزيد الاول، إذ استخدم مع الإمارات التركمانية سياسية

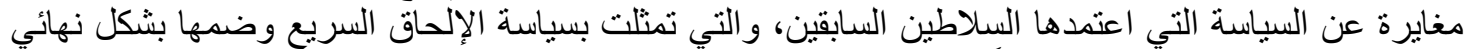
للاولة العثمانية، وظهر هذا واضية اضحاً خلال الحملات العسكرية التي قادها السلطان بايزيد الاول ضد الإندان الإمارات

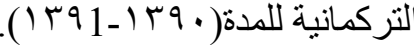

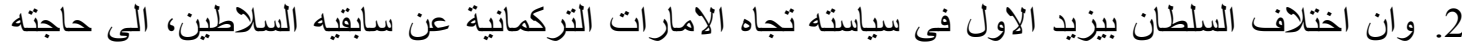

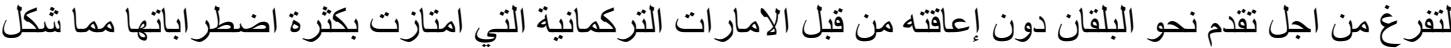

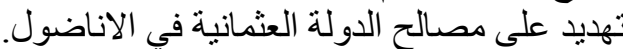

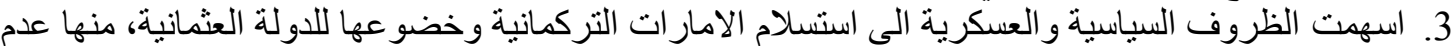

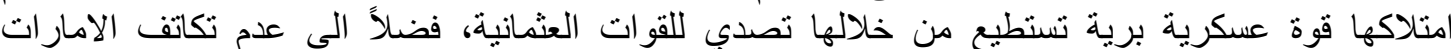

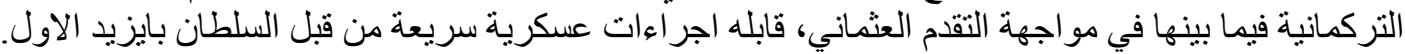

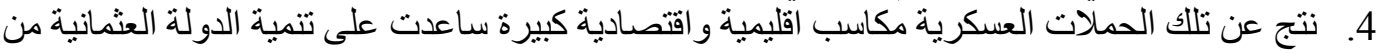

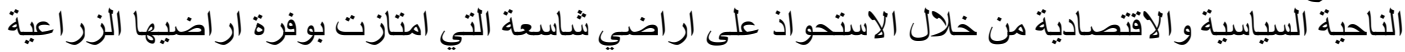

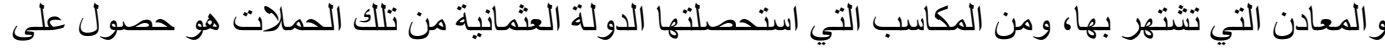
مو انئ و اساطيل بحرية التي استفادت منها من خلال التجارة او الحملات العسكرية البحرية التي قامت بهان فئ فيما 


\section{مجلة العلوم التربوية والإنسانية}

Journal of Educational and Human Sciences

www.jeahs.com

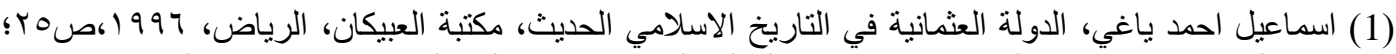

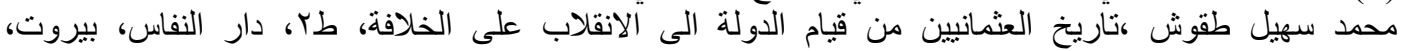

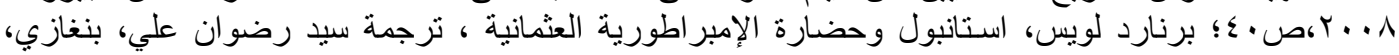

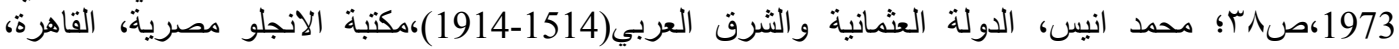

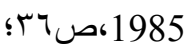

Stanford Shaw, History of the Ottoman Empire and Modern Turkey: Empire of the Gazis: The Rise and Decline of the Ottoman Empire 1280-1808, Vol I, Cambridge, 2002, p.21.

(2)رائد سامي حميد الدوري، الدولة العثمانية في عهد السلطان مراد الاول 1359-1389،اطروحة دكتوراه غير

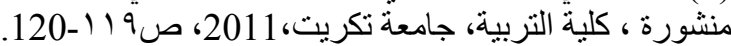

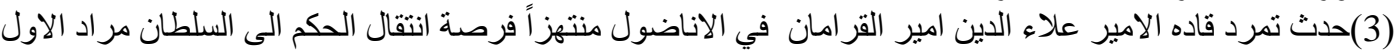

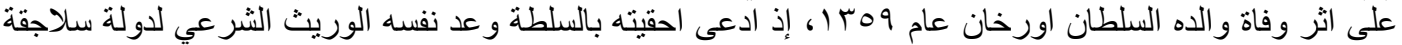

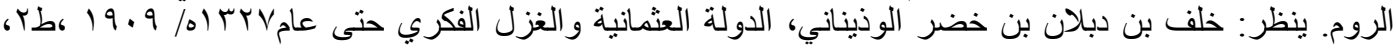

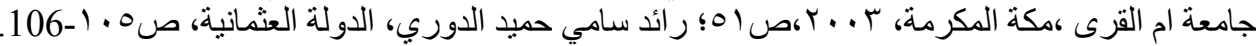

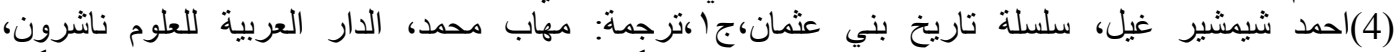

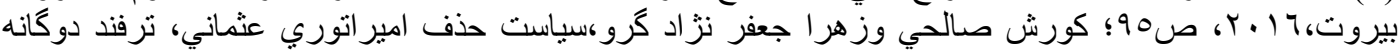

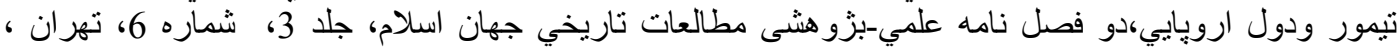
.350، 2016

(5)Leslie P. Peirce, The Imperial Harem: Women and Sovereignty in the Ottoman Empire (Studies in Middle Eastern History), Oxford University Press, USA, 1993,p.36 ؛ Stanford Shaw, Op.Cit , p.28؛ Colin Imber, The Ottoman Empire 1300-1650 The Structure of Power, Mackays of Chatham, Great Britain, 2002, p.93; Enes Mert Demir ,Yıldırım Bayezid Dönemi Fetihlerinin Osmanlı Merkezileşmesine Etkisi ,Uluslararası Yıldırım Bayezid Sempozyumu Bildiriler Kitab1 - Türk Tarih Kurumu, 2015,s.29.

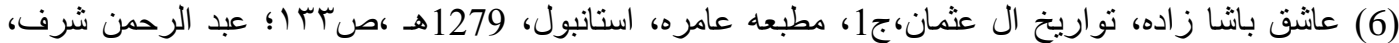

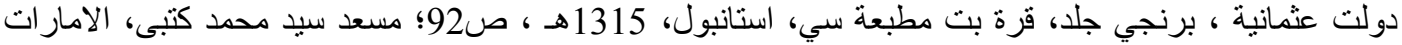

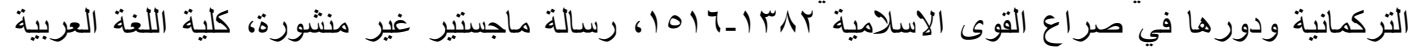

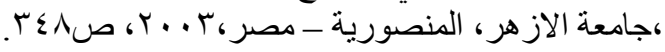

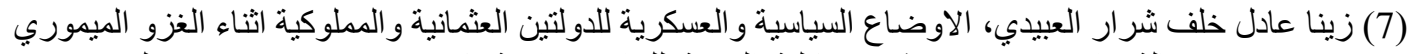

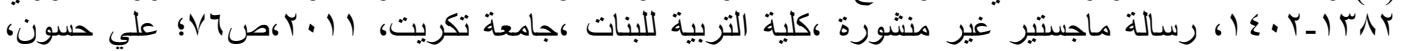

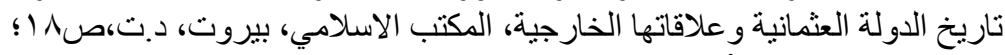

Halil İnalcik, Has-Bağçede Ayş u Tarab - Nedimler Şairler Mutripler, İş Bankası Kültür Yay, İstanbul,2011,s.112.

(8) كير شهري: مدينة تقع في الاناضول شرق بحيرة طوز كولي. ينظر: س. موستراس، المعجم الجغرافي

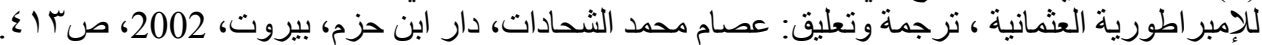

(9)Müneccimbaşı Ahmet b. Lütfullah ، Camiü'd-Düvel Osmanlı Tarihi (1299-1481)،Yay. haz. ve çev. Ahmet Ağırakça، İstanbul،1995 ‘s.133; Stanford Shaw, Op.Cit , p.28-29؛ روبير مانتران، ، تاريخ الدولة العثمانية، ج1، ترجمة: بشير السباعي، دار الفكر للار اسات والنشر والتوزيع، القاهرة،

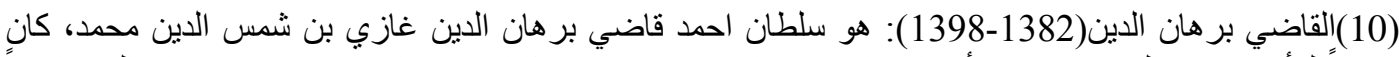

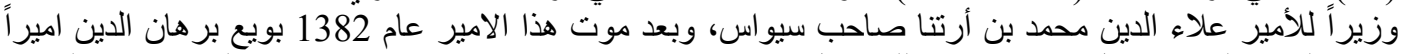

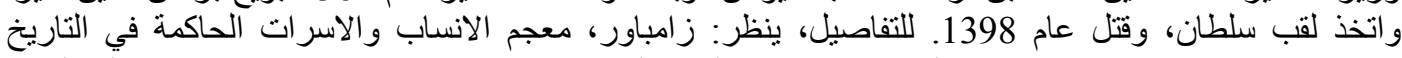

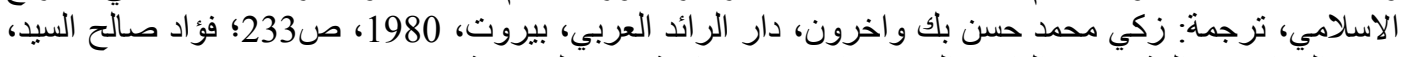

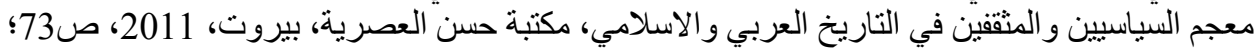


Willam C. Chiltlick, Sullan Burhan Al-din's Sufi Correspondence, Wiener Zeitschrift für die Kunde des Morgenlandes, Department of Oriental Studies, University of Vienna, Vol. 73, 1981, p. 33-45.

(11) روبير مانتران، المصدر السابق،صالآ62؛ على جواد، مكمل عنمانلي تاريخي، قصبار مطبعة سنده،

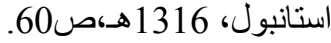

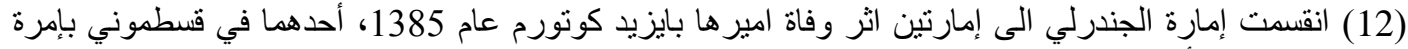

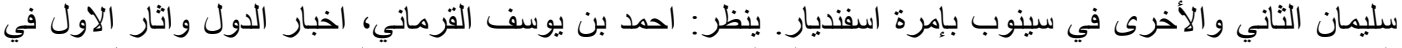

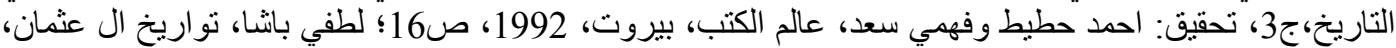

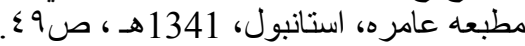

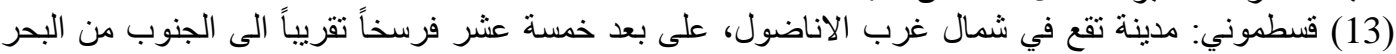

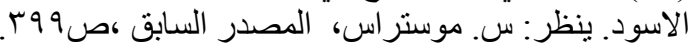

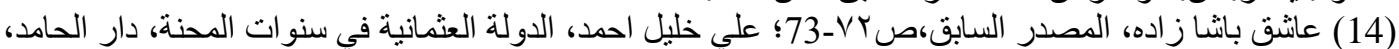

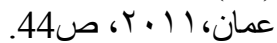

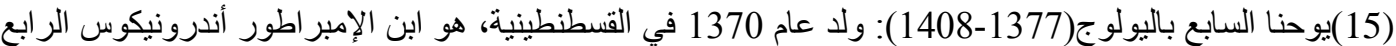

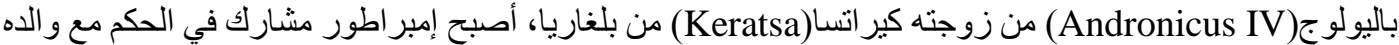

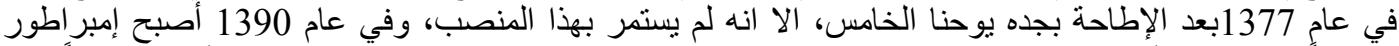

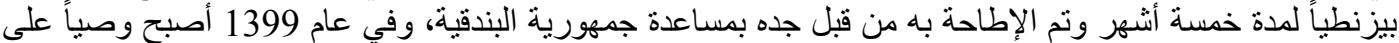

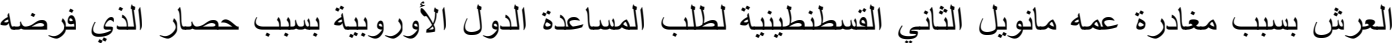

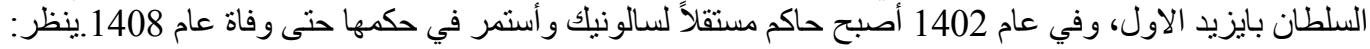
Franz Dölger, Johannes VII. Kaiser der Rhomäer, Byzantinische Zeitschrift, Vol. 31 ,Berlin ,1931, p.21-36.

Halil İnalcik,A.G.E.,s.112.

$$
\text { روبير مانتران، الدصدر السابق، ص62؛ }
$$

(17)Stanford Shaw, Op.Cit , p.30; H.A. Gibbons, The Foundation of The Ottoman Empire(1300-1403), Oxford ,1916, p.188.

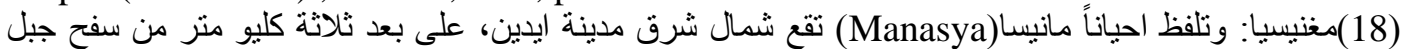

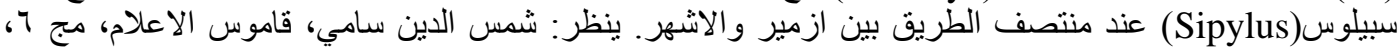

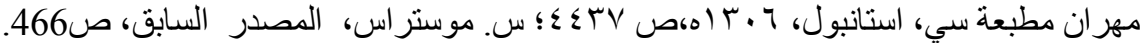

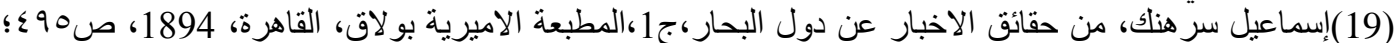

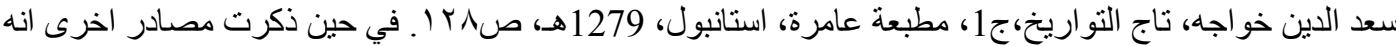

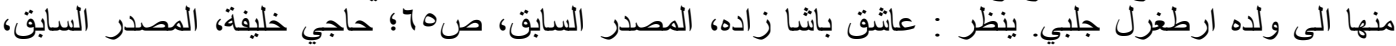

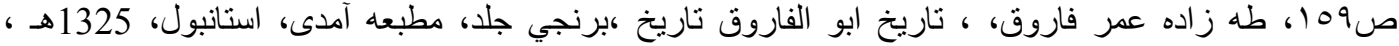

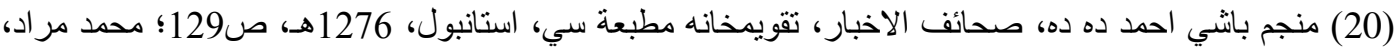

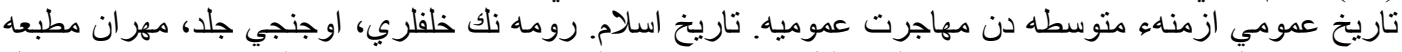

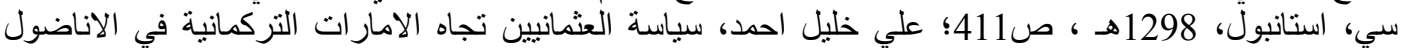

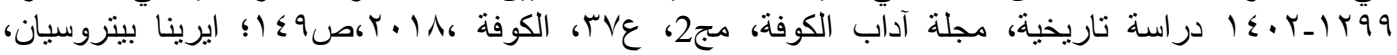

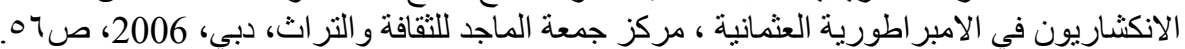

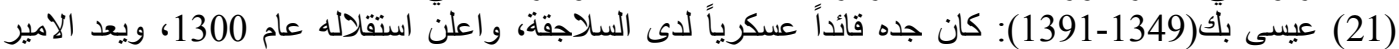

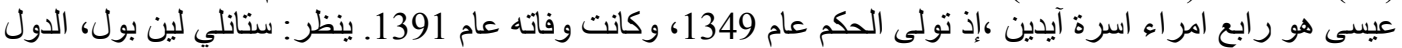

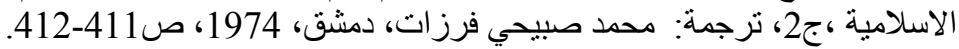

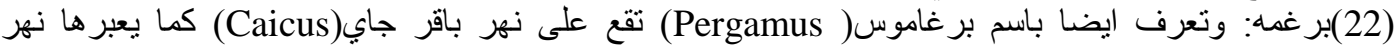

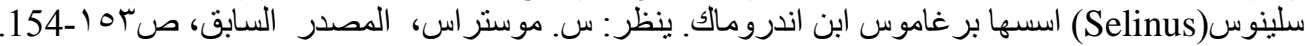

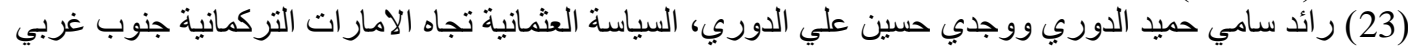

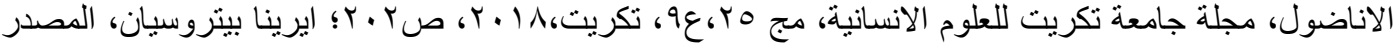

H.A. Gibbons, Op.Cit, p.185.

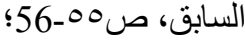




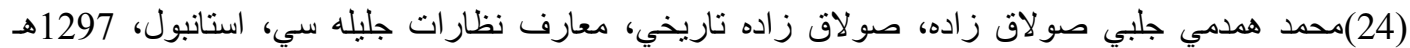

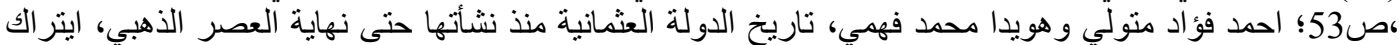

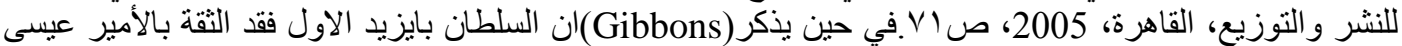

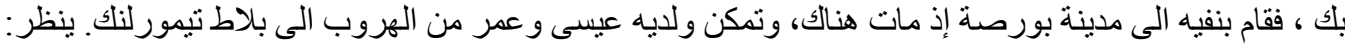
H.A. Gibbons, Op.Cit, p.185.

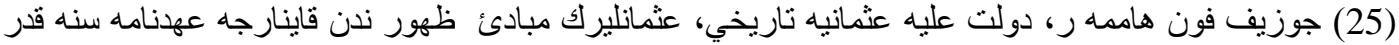

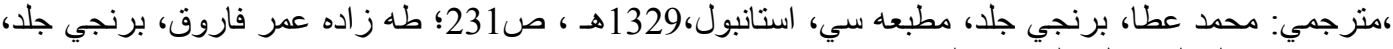

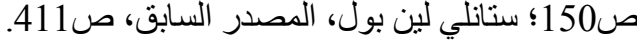

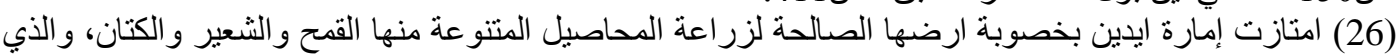

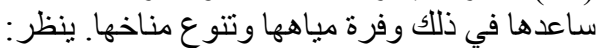
Kate Fleet, European and Islamic Trade in the Early Ottoman State: The Merchants of Genoa and Turkey (Cambridge Studies in Islamic Civilization), Cambridge University Press , United Kingdom, 1999, p.50-79.

(27)حسن روملو، احسن التواريخ ،تصحيح جالسن نارين سيدت، در مطبعة بيتست مشن بريس كلكته، بطبع

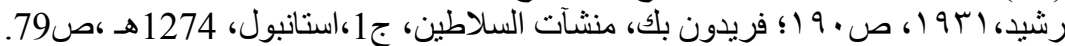

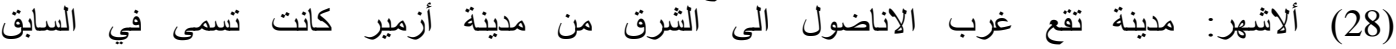

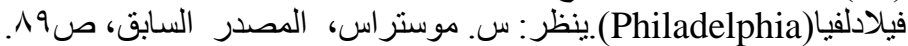

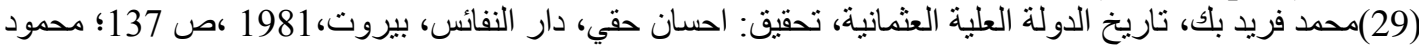

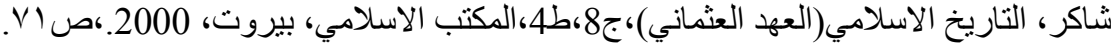

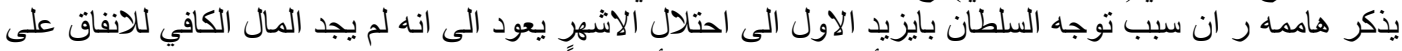

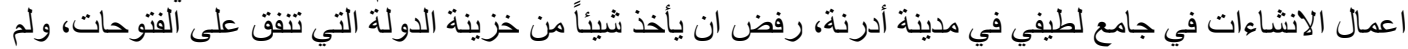

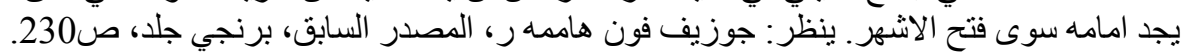

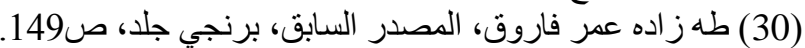

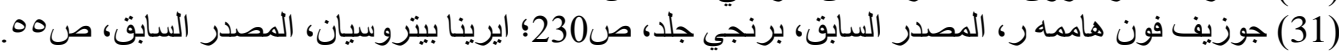

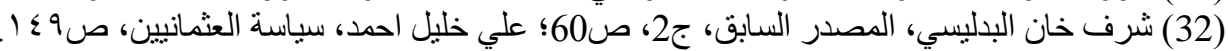

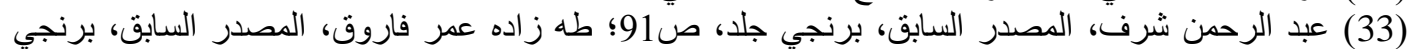

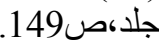

(34) إبيسالا: و هي جزيرة في الارخبيل تقع الى الغرب من جزيرة خيوس، و الى الجنوب من جزيرة ليسبوس، شمال

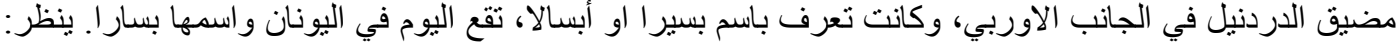

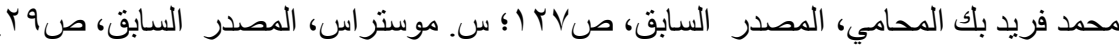

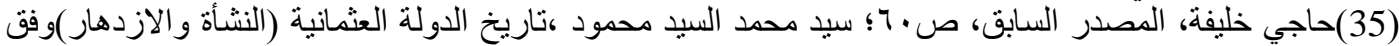

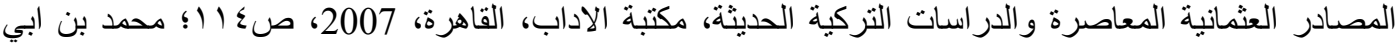

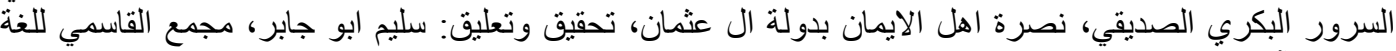

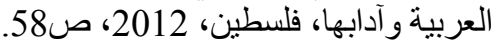

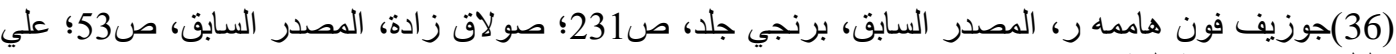

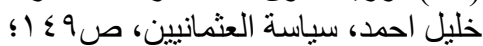
Mehmed Neşri, Mehmed Neşri, Gihan-Nüma " Neşri Tarihi", Yayınlayanlar:Faik Reşit Unat Mehmed A. Köymen, Gilt: I., Türk Tarih Kurumu Basımevi, Ankara,1957,s.312.

(41) إسبرطة : مدينة تقع في الاناضول ضمن املاك إمارة حميد ، وهي غير مدينة إسبارطة اليونانية الششهورة.

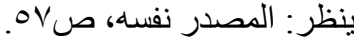

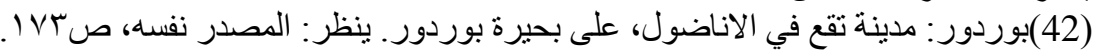

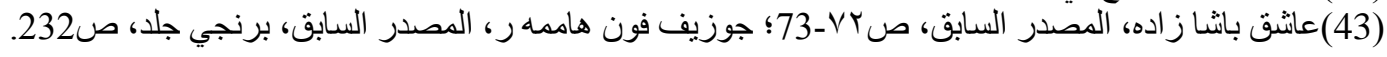




\section{مجلة العلوم التربوية والإنسانية}

Journal of Educational and Human Sciences

www.jeahs.com

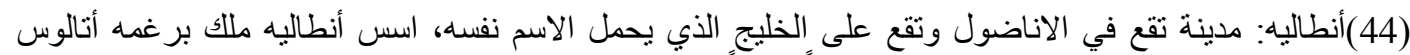

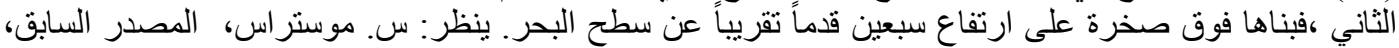

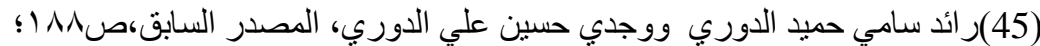

Karen Barkey, Empire of Difference the Ottoman in Comparative Perspective, Cambridge University Press, Now York, 2008,p.30; H.A. Gibbons, Op.Cit, p.186-187.

(46)في حين ذكر ان تم تعيين فيروز بك حاكماً على إمارة تكة. ينظر : صولاق زلئ ادة، المصدر السابق، ص54.

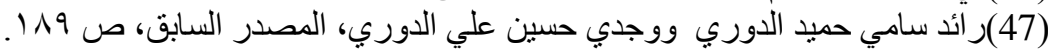

(48) H.A. Gibbons, Op.Cit, p.185.

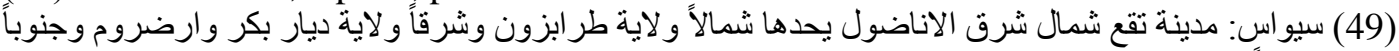

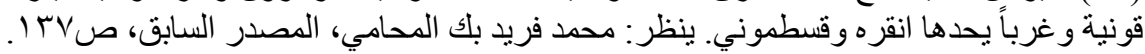

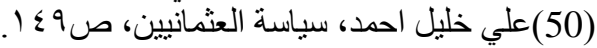

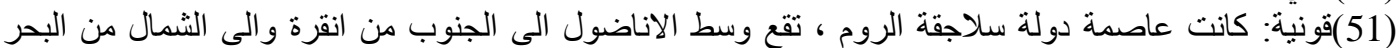

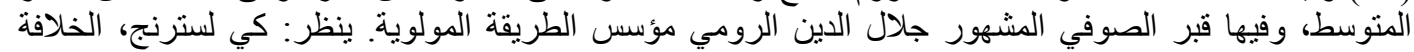

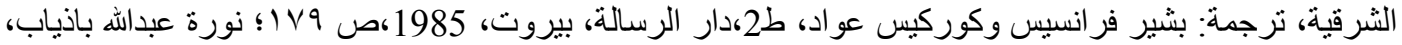

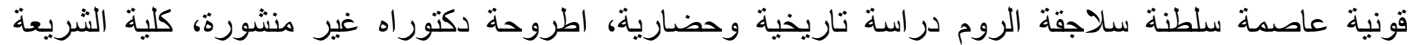

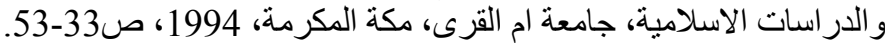
(52) طاش أيلي: تعرف باسم قيليقية(Kilikia)، هو القليم في جنوبة شرق الإنة الاناضول حدودها جبال طوروس و البحر

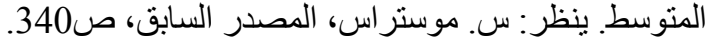
(53)جوزيف فون هاممه ر، الدصدر السابق، برنجي جلد، صنئ، ص232؛؛ سيد محمد السيد محمود، المصدر السابق، ص1116-110

H.A. Gibbons, Op.Cit, p.187; Halil İnalcik,A.G.E.,s.112.

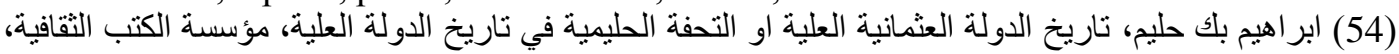

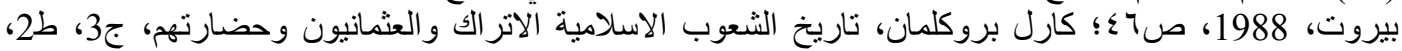

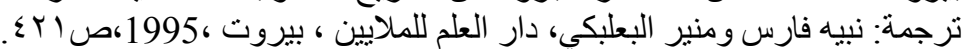

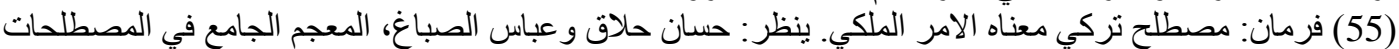

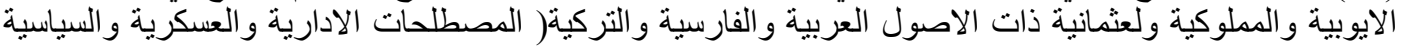

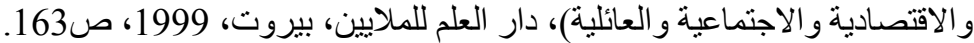
(56) للتفاصيل عن الروايات التي رويت عن غصب وصارين لارمة السلطان بايزيد الاول، ينظر : Tarkan Suçıkar, XV-XVII.Yüzyıl Osmanlı Kaynaklarında Yıldırım Bayezid Ve Timur Algısı,Yüksek Lisans Tezi, Fatih Sultan Mehmet Vakıf Üniversiteleri, Sosyal Bilimler Enstitüsü ,Türkiye, 2014, s.119-126.

(57) منجم بانثي احمد ده ده، المصدر السابق، ص130؛ علي جواد، المصدر السابق، ص26؛ احمد شيمشير غيل،

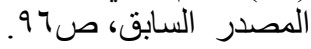

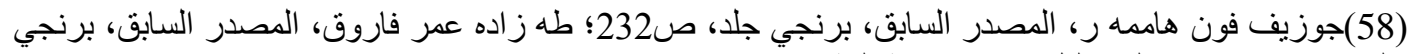

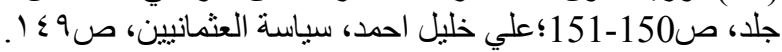

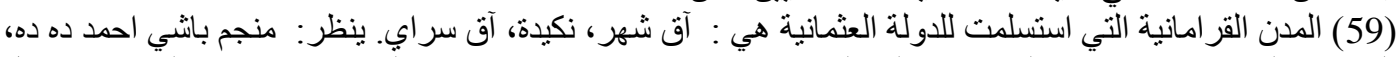

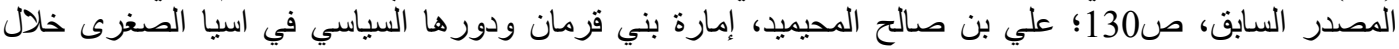

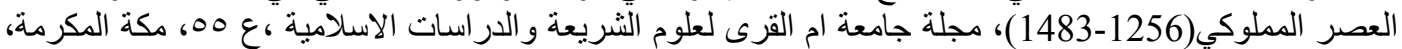

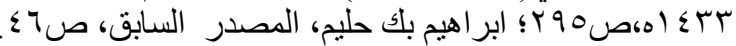

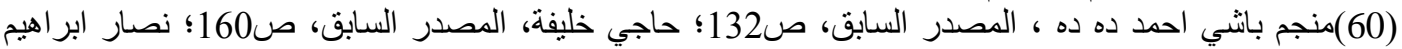

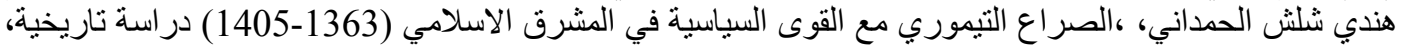

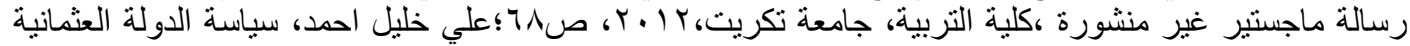

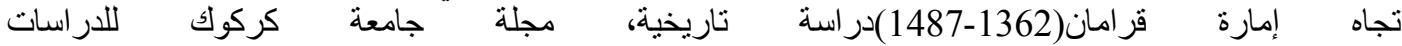

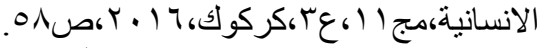

Stanford Shaw, Op.Cit , p.30. (61) نهر جهار شنبة: نهر يقع في سهل قونية. ينظر : 


\section{مجلة العلوم التربوية والإنسانية}

Journal of Educational and Human Sciences www.jeahs.com

(62) لارندة: مدينة تقع في جنوب الاناضول، و يقع الى الغرب منها بك شهر و الى الثمال قونية والى الثرق بحر

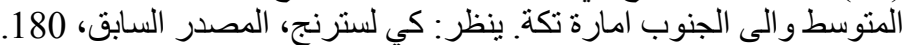

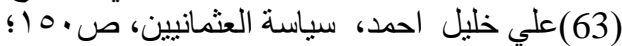

Halil İnalcik,A.G.E.,s.112.

H.A. Gibbons, Op.Cit, p.187.

1. رائد سامي حميد الدوري، الدولة العثمانية في عهد السلطان مر اد الاول 1359-1389،اطروحة دكتور اه غير منشورة ، كلبة التربية، جامعة تكريت، النيا، 2. زينا عادل خلف شر ار العبيدي، التربة الاوضاع السياسية والعسكرية للدولتين العثمانية و المملوكية اثناء الغزو

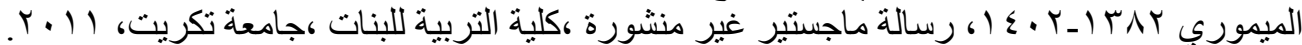

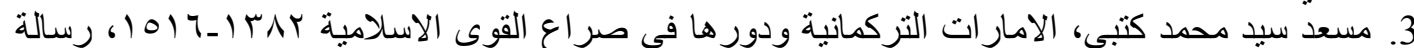

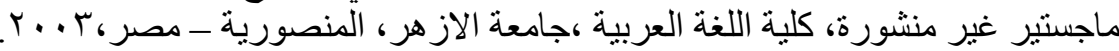

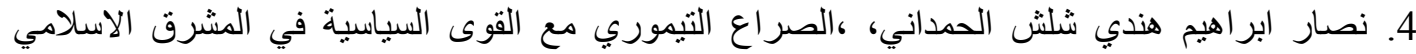

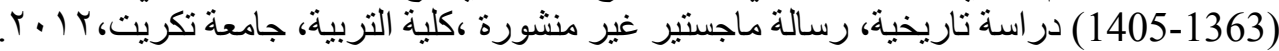

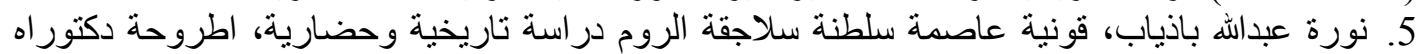
غير منشورة، كلية الثريعة و الدر اسات الاسلامية، جامعة ام القرى، مكة المكرمة، 1994.

1. Tarkan Suçıkar, XV-XVII.Yüzyıl Osmanlı Kaynaklarında Yıldırım Bayezid Ve Timur Algısı,Yüksek Lisans Tezi, Fatih Sultan Mehmet Vakıf Üniversiteleri, Sosyal Bilimler Enstitüsü ,Türkiye, 2014.

$$
\text { أثانياً: الكتبة: العثمانية المدونة بالحروف العربية: }
$$

1. جوزيف فون هاممه ر، دولت عليه عثمانيه التيه تاريخي، عثمانليرك مبادئ ظهور ندن قاينارجه عهدنامه سنه

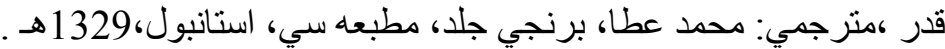
2. حسن روملو، احسن التواريخ ،تصحيح جالسن نارين سيدت، در مطبعة بيتست مشن بريس كلكته، بطبع رشيد، 1931 رين

3. سعد الدين خو اجه، تاج التواريخ، ج1، مطبعة عامرة، استانبول، 1931 1279هـ.

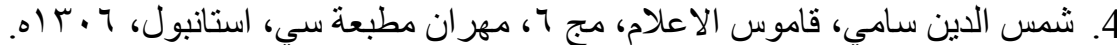

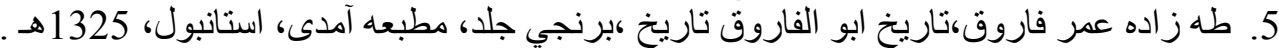

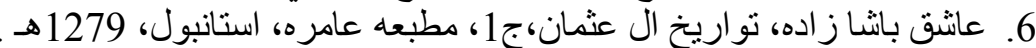

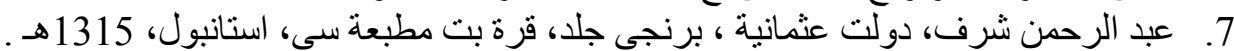

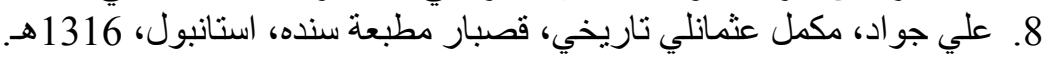

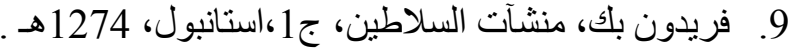
10.

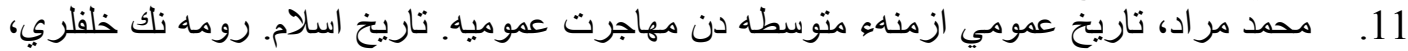

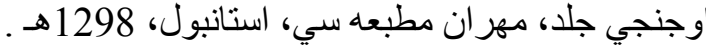
12. محمد همدمي جلبي صولاق هي، زاده، صولاق زاني، زاده تاريخي، معارف نظارات جليله سي، استانبول، 


\section{مجلة العلوم التربوية والإنسانية}

Journal of Educational and Human Sciences www.jeahs.com

13. منجم بانشي احمد ده ده، صحائف الاخبار ، تقويمخانه مطبعة سي، استانبول، 1276 هـ.

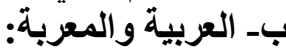
1. ابر اهيم بك حليم، تاريخ الدولة العثمانية العلية او التحفة الحليمية في تاريخ الدولة العلية، مؤسسة الكتب

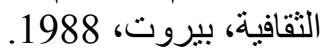
2. احمد بن يوسف القرماني، اخبار الدول واثار الاول في التاريخ،ج3، تحقيق: احمد حطيط وفهي سعد،

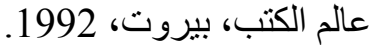
3. احمد شيمشير غيل، سلسلة تاريخ بني عثمان،ج (كترجمة: مهاب محمد، الدار العربية للعلوم ناشرون،

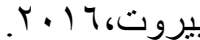
4. احمد فؤاد منولي و هويدا محمد فهمي، تاريخ الدولة العثمانية منذ نشأتها حتى نهاية العصر الذهبي، ايتر الك

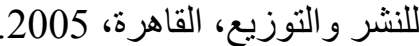

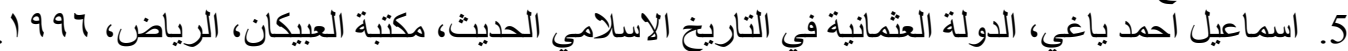

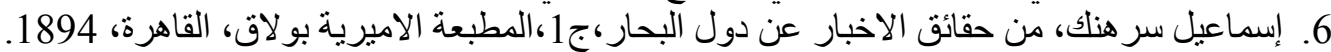

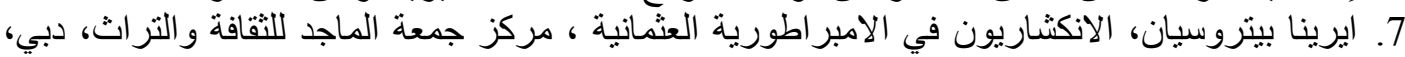
2006

8. برنارد لويس، استانبول وحضارة الإمبر اطورية العثمانية ، ترجمة سيد رضوان الإن علي، بنغازي، 1973.

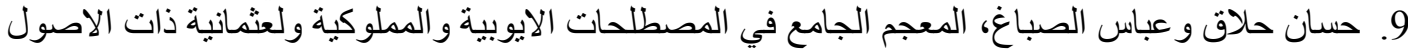
العربية و الفارسية و النركية( المصطلحات الادارية و العسكرية و السياسية و الاقتصادية والاجنية الإنماعية و العائلية)، دار العلم للملايين، بيروت، ولتركن 1999.

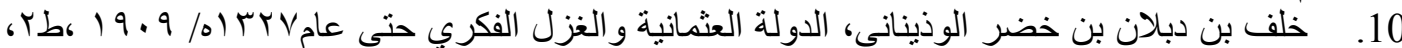

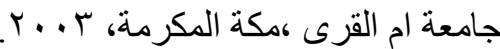
11. روبير مانتران، تاريخ الدولة العثمانية، ج1، ترجمة: بشير السباعي، دار الفكر للاراسات والنشر

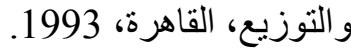
12. زامباور، معجم الانساب والاسرة الدرات الحاكمة في التاريخ الاسلامي، ترجمة: زكي محمد حسن بك

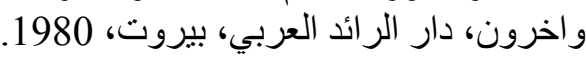
13. س. موستر اس، المعجم الجغر افي للإمبر اطورية العثمانية ، ترجمة وتعليق: عصام محمد الثحادات،

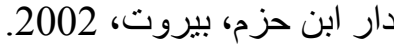

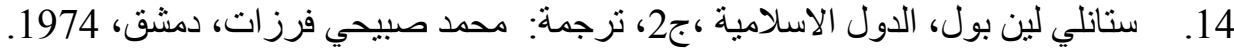

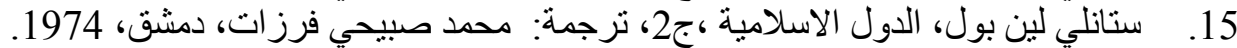

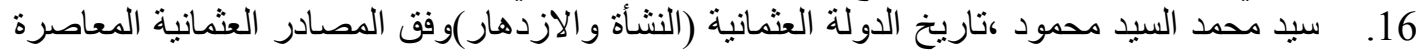

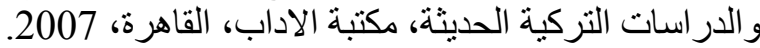

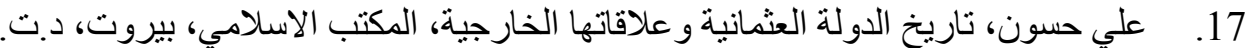

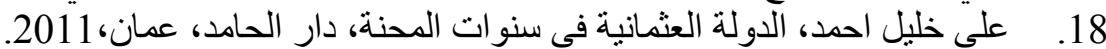

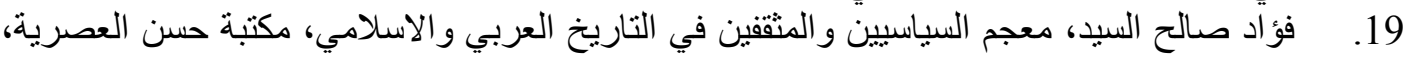

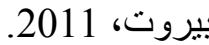
20. كارل بروكلمان، تاريخ الشعوب الاسلامية الاتر الك و العثمانيون وحضارتهم، ج3، ط2، نرجمة: نبيه

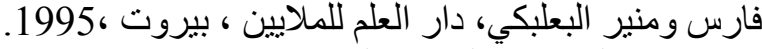
21. كي لسترنج، الخلافة الثرقية، ترجمة: بشير فرانسيس وكوركيس عواد، ط2،دار الرسالة، بيروت،

22. محمد انيس، الدولة العثمانية و الثرق العربي(1514-1914)،مكتبة الانجلو مصرية، القاهرة، 1985. 23. محمد بن ابي السرور البكري الصديقي، نصرة الهل الايمان بدولة ال عثمان، تحقيق وتعليق: سليم ابو التئية

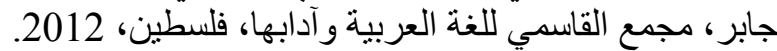

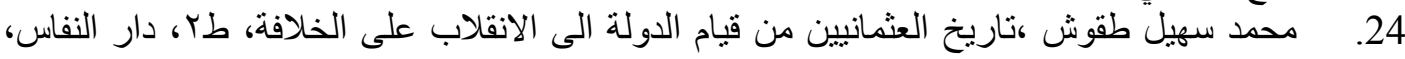




\section{مجلة العلوم التربوية والإنسانية}

Journal of Educational and Human Sciences www.jeahs.com

$$
\begin{aligned}
& \text { 25. محمد فريد بك، تاريخ الدولة العلية العثمانية، تحقيق: احسان حقي، دار النفائس، بيروت، العي، } 1981 .
\end{aligned}
$$

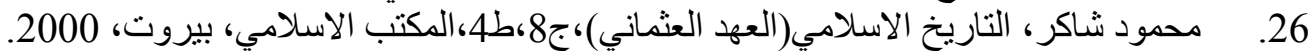

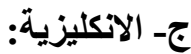

1. Colin Imber, The Ottoman Empire 1300-1650 The Structure of Power, Mackays of Chatham, Great Britain, 2002.

2. Franz Dölger, Johannes VII. Kaiser der Rhomäer, Byzantinische Zeitschrift ,Vol. 31 ,Berlin ,1931.

3. H.A. Gibbons, The Foundation of The Ottoman Empire(1300-1403) ,Oxford 1916.

4. Karen Barkey, Empire of Difference the Ottoman in Comparative Perspective, Cambridge University Press, Now York, 2008.

5. Kate Fleet, European and Islamic Trade in the Early Ottoman State: The Merchants of Genoa and Turkey (Cambridge Studies in Islamic Civilization), Cambridge University Press ,United Kingdom, 1999.

6. Leslie P. Peirce, The Imperial Harem: Women and Sovereignty in the Ottoman Empire (Studies in Middle Eastern History), Oxford University Press, USA, 1993.

7. Stanford Shaw, History of the Ottoman Empire and Modern Turkey: Empire of the Gazis: The Rise and Decline of the Ottoman Empire 1280-1808, Vol I, Cambridge, 2002.

$$
\text { دـ التركية المدونة بالحروف اللاتينية: }
$$

1. Halil İnalcik, Has-Bağçede Ayş u Tarab - Nedimler Şairler Mutripler, İș Bankası Kültür Yay ,İstanbul,2011.

2. Mehmed Neşri, Mehmed Neşri , Gihan-Nüma " Neşri Tarihi", Yayınlayanlar:Faik Reşit Unat Mehmed A. Köymen, Gilt: I., Türk Tarih Kurumu Basımevi, Ankara,1957.

3. Müneccimbaşı Ahmet b. Lütfullah 'Camiü’d-Düvel Osmanlı Tarihi (12991481)،Yay. haz. ve çev. Ahmet Ağırakça ،İstanbul،1995.

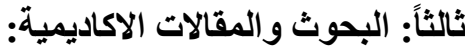

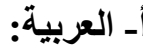

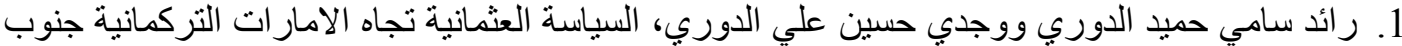

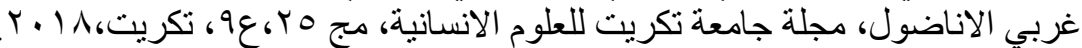

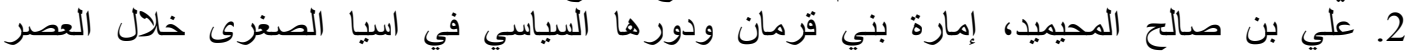

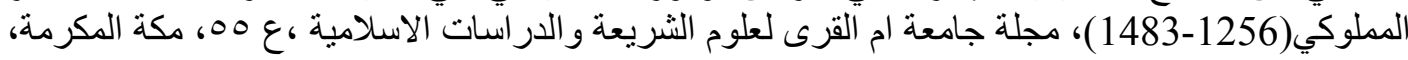

$$
\begin{aligned}
& \text {.0) } \leqslant \text { r } \\
& \text { 3. علي خليل احمد، سياسة الدولة العثمانية تجاه إمارة قر امان(1362-1487)در اسة تاريخية، مجلة جامعة }
\end{aligned}
$$

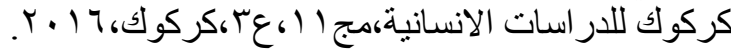

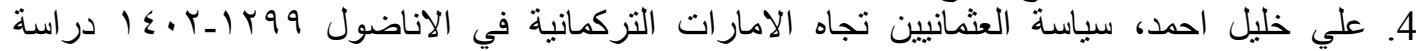

$$
\begin{aligned}
& \text { تاريخية، مجلة آداب الكوفة، مج2، على"، الكوفة ،2018. }
\end{aligned}
$$

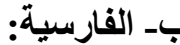

$$
\begin{aligned}
& \text { 1. كورش صالحي وزهرا جعفر نزاد كرو،سياست حذف امير اتوري عثماني، نرفند دوكانه تبمور ودول }
\end{aligned}
$$

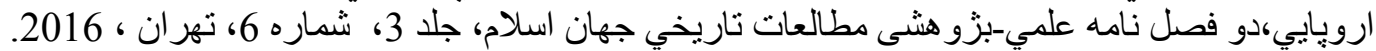




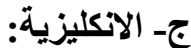

1. Willam C. Chiltlick, Sullan Burhan Al-din's Sufi Correspondence, Wiener Zeitschrift für die Kunde des Morgenlandes, Department of Oriental Studies, University of Vienna, Vol. 73, 1981.

$$
\text { دـ التركية المدونة بالحروف اللاتينية: }
$$

1. Enes Mert Demir ,Yıldırım Bayezid Dönemi Fetihlerinin Osmanlı Merkezileşmesine Etkisi ,Uluslararası Yıldırım Bayezid Sempozyumu Bildiriler Kitabı - Türk Tarih Kurumu, 2015. 